\title{
On Multidisciplinary Potential Applications of Gauge Theories
}

\author{
Jean Pierre Magnot* \\ Department of of Mathematics, University of Angers, France
}

Submission: January 29, 2018; Published: May 22, 2018

*Corresponding author: Jean-Pierre Magnot, Department of of Mathematics, University of Angers, France; Email: jp.magnot@gmail.com

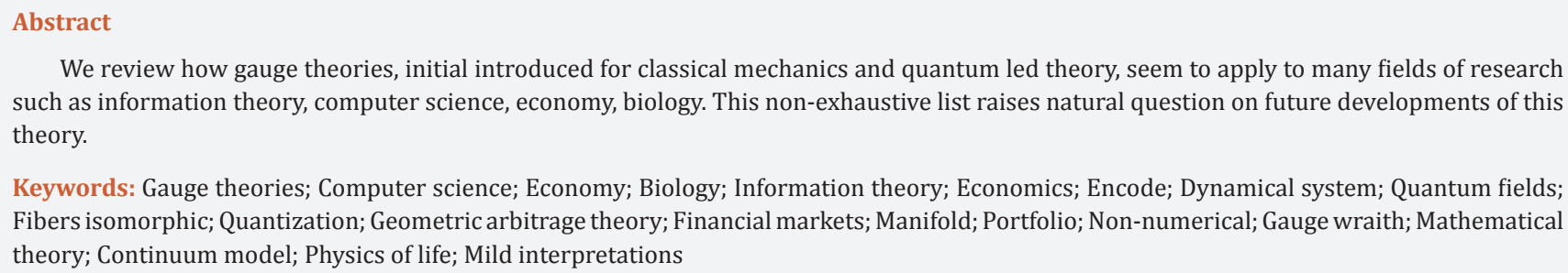

We review how gauge theories, initial introduced for classical mechanics and quantum led theory, seem to apply to many fields of research such as information theory, computer science, economy, biology. This non-exhaustive list raises natural question on future developments of this theory.

Keywords: Gauge theories; Computer science; Economy; Biology; Information theory; Economics; Encode; Dynamical system; Quantum fields; Fibers isomorphic; Quantization; Geometric arbitrage theory; Financial markets; Manifold; Portfolio; Non-numerical; Gauge wraith; Mathematical theory; Continuum model; Physics of life; Mild interpretations

\section{Short Communication}

\section{How gauge theories appear in information theory and economics}

Basically, the mathematical structure of groups is among the best adapted for describing transformations and moves. A path on a group can encode the evolution of a dynamical system, or the moves of an exterior observer with respect to a given system. In the theory of quantum fields, more general objects called principal bundles, which consist in a total space $P$ with fibers isomorphic to a (Lie) group $G$ over a base (simplicial complex or manifold) $M$. For one of the most simple settings, one can see when the base is a manifold (we call them continuum gauge theories) [1-5]. When the base is a simplicial complex (or a lattice), the models are called discrete gauge theories. They stand formally as an integrated version of the previous ones which (more or less formally again). The physical study consists in solving equations on $P$ or after quantization into fields, in minimizing so-called action functionals. These action functionals are in fact acting on connections, which are infinitesimal expressions of local slices. They can be understood also as differential operators. These delicate settings coming from physics have, in the last twenty years, found two applications to our knowledge:

In so-called "geometric arbitrage theory» for managing portfolios in financial markets [2,6-10], where fiber bundles or principal bundles describe, along their fibers and on the base, the external and internal parameters for the prediction of the evolution of the portfolio. Fiber bundles over a manifold described in [9] are related to principal bundles in a way described in [10].
In so-called approximate reasoning in pairwise comparisons where complete studies can be performed when $G=\mathbb{R}_{+}^{*}$ and with normalized objects, with very recent axiomatization [1019]. However, the need of so-called non-numerical ranking appeals the use of non-abelian groups $G$ and of mathematical tools coming from discrete gauge theories $[12,18]$.

\section{Gauge wraith in biology and neurology}

The aim of this short article, giving the opinion of the sole author, is to mention that there are some hidden aspects of neurology and biology which reveal, in some kind of matching mirror process, the presence of gauge effects. This aspect is not actually truly confirmed, it is more-or-less at a step of conceptualization, and that is the reason why we talk of gauge wraith. Other authors have already mentioned the similarities of models coming from biology and neuronal science $[11,15,16]$, each time with very mild interpretations of classical facts. From a heuristic viewpoint, this is not so surprising since «physics of life» deal with entities interacting with each other, exactly like elementary particles of nuclear physics interact. At the microscopic scale, a simplicial structure arise naturally by linking an entity (neuron, molecule, cell) with each of its neighbours making discrete gauge theories appropriate, and at macroscopic level, a first approximation of phenomena can rise form continuum gauge theories. However, as a last remark, the mathematical theory of discretization of gauge theories has to be questioned very seriously, because the classical scheme based on leads to mathematical problems while other still non studied ways to discretize a continuum model can be proposed [17]. 


\section{References}

1. Cavallo B, Dapuzzo L, Squilllante M (2010) Pairwise Comparison Matrices over abelian Linearly Ordered Groups: A Consistency Measure and Weights for the Alternatives. Multicriteria and Multiagent Decision Making with Applications to Economics and Social Sciences 305: 49-64.

2. Farinelli S (2015) Geometric arbitrage theory and market dynamics. J Geom Mech 7(4): 431-471.

3. Janicki R (2009) Pairwise Comparisons Based Non-Numerical Ranking; Fundamenta Informaticae 94(2): 197-217

4. Koczkodaj WW, Magnot JP, Mazurek J, Peters JF, Rakhshani H, et al. (2017) On normalization of inconsistency indicators in pairwise comparisons International Journal of Approximate Reasoning 86: 7379.

5. Koczkodaj WW, Magnot JP (2016) A Geometric Framework for the Inconsistency in Pair-wise Comparisons; extended version of arXiv:1601.01301.

6. Koczkodaj WW, Szwarc R (2014) Axiomatization of Inconsistency Indicators for Pairwise Com-parisons. Fundamenta Informaticae 132(4): 485-500.

7. Koczkodaj WW, Sybowski J (2015) Axiomatization of Inconsistency Indicators for Pairwise Comparisons Matrices.

8. Koczkodaj WW, Urban R (2018) Axiomatization of inconsistency indicators for pairwise comparisons International Journal of Approximate Reasoning 94: 18-29.

This work is licensed under Creative Commons Attribution 4.0 Licens DOI: 10.19080/BBOJ.2018.07.555701
9. Kolar I, Michor PW, Slovak J (1993) Natural operations in differential geometry, Springer, USA.

10. Kriegl A, Michor PW (2000) The convenient setting for global analysis Mathematical surveys and monographs, American Mathematical Society, 53: 1-611.

11. Mack G (1995) Gauge theory of things alive. Nucl Phys B Proc Suppl 42: 923-925.

12. Magnot JP (2018) A mathematical bridge between discretized gauge theories in quantum physics and approximate reasoning in pairwise comparisons Adv Math Phys p. 1-5.

13. Magnot JP (2017) On pairwise comparisons with values in a group: algebraic structures, geometric and probabilistic aspects.

14. Sengupta AN (2008) Gauge Theory in Two Dimensions: Topological Geometric and Probabilistic Aspects. In: Gerard BA, et al. (Eds.), Stochastic Analysis in Mathematical Physics, World Scienti c.

15. Sengupta B, Tozzi A, Cooray GK, Douglas PK, Friston KJ (2016) Towards a Neuronal Gauge Theory. PLoS Biol 14(3): e1002400.

16. Tozzi A, Peters JF, Cha C, De Falco D, Torday JS (2018) A timeless biology, Progress in Biophysics and Molecular Biology.

17. Whitney H (1957) Geometric Integration Theory, Princeton University Press, Princeton, New Jersey, USA.

18. Young K (1999) Foreign exchange market as lattice gauge theory. Am J Phys 67(10): 862-868.

19. Zhai Y (201) Non numerical ranking based on pairwise comparisons PhD thesis, Mc Master university, Hamilton, Ontario, Canada.

\section{Your next submission with Juniper Publishers} will reach you the below assets

- Quality Editorial service

- Swift Peer Review

- Reprints availability

- E-prints Service

- Manuscript Podcast for convenient understanding

- Global attainment for your research

- Manuscript accessibility in different formats

( Pdf, E-pub, Full Text, Audio)

- Unceasing customer service

Track the below URL for one-step submission https://juniperpublishers.com/online-submission.php 